\title{
A novel algorithm for the computation of the diastolic pressure ratio in the invasive assessment of the functional significance of coronary artery disease
}

\author{
Francesco VERSACI 1, Micaela CONTE 2, Marcel VAN'T VEER 3, Sébastien LALANCETTE 4, \\ Keith OLDROYD ${ }^{5}$, Simone CALCAGNO ${ }^{1}$, Giuseppe BIONDI ZOCCAI 6,7 *
}

${ }^{1}$ Department of Cardiology, Santa Maria Goretti Hospital, Latina, Italy; ${ }^{2}$ Department of Cardiology, Clinic Saint Jean, Brussels, Belgium; ${ }^{3}$ Catharina Hospital, Eindhoven, the Netherlands; ${ }^{4}$ Opsens Medical, Québec, ON, Canada; 5 West of Scotland Heart and Lung Centre,

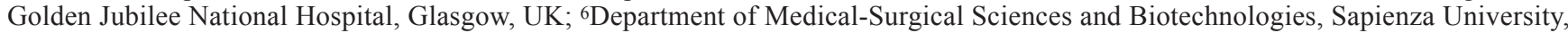
Latina, Italy; ${ }^{7}$ Mediterranea Cardiocentro, Naples, Italy

*Corresponding author: Giuseppe Biondi Zoccai, Department of Medical-Surgical Sciences and Biotechnologies, Sapienza University of Rome, Latina, Italy. E-mail: giuseppe.biondizoccai@uniroma1.it

\section{A B S T R A C T}

BACKGROUND: Invasive functional assessment is a mainstay in the management of patients with coronary artery disease (CAD), but there is uncertainty on the comparative accuracy of diagnostic indices of functional significance. We aimed to validate the diagnostic performance of a novel non-hyperemic diastolic pressure ratio (dPR).

METHODS: We performed a retrospective analysis including two separate registries (VERIFY 2, Latina, Italy) of patients in whom functional indices were measured for lesions with angiographically moderate severity. On top of fractional flow reserve, distal coronary pressure (Pd)/aortic pressure $(\mathrm{Pa})$ ratio, instantaneous wave-free ratio (iFR) and diastolic pressure ratio (dPR) were computed using a novel dedicated algorithm over 4 consecutive beats. Agreement/discrepancy between indexes was appraised Bland-Altman analysis, area under the receiver operating characteristic curve (AUC), and unsupervised machine learning.

RESULTS: A total of 525 lesions from 479 patients were included. The novel dPR was highly correlated with iFR $\left(\mathrm{R}^{2}=0.99\right.$, $\left.\mathrm{P}<0.001\right)$, with a mean difference of $-0.004 \pm 0.014$. The diagnostic performance of dPR (best cutoff value: $\leq 0.89$ ) against iFR was as follows: accuracy $=96 \%$; sensitivity $=94 \%$; specificity $=97 \%$; positive-predictive value $=94 \%$; and negative-predictive value $=96 \%$. Additionally, AUC to predict iFR $\leq 0.89$ was 0.99 , which was significantly higher than that of $\mathrm{Pd} / \mathrm{Pa}(0.97, \mathrm{P}<0.001)$. In the iFR range of $0.85-0.93$ ("grey zone"), the diagnostic performance was well maintained (accuracy $=91 \%$; sensitivity $=87 \%$; specificity $=93 \%$; and AUC $=0.96$ ). Results were supported also by unsupervised learning analysis.

CONCLUSIONS: This multicenter registry suggests this novel dPR algorithm provides results that are numerically equivalent to iFR. Pending further studies, physicians may consider using this novel dPR algorithm to gauge the functional significance of a coronary lesion.

(Cite this article as: Versaci F, Conte M, van't Veer M, Lalancette S, Oldroyd K, Calcagno S, et al. A novel algorithm for the computation of the diastolic pressure ratio in the invasive assessment of the functional significance of coronary artery disease. Panminerva Med 2021;63:206-13. DOI: 10.23736/S0031-0808.20.04202-0)

KEY WORDS: Coronary artery disease; Fractional flow reserve, myocardial; Algorithms.

C Coronary artery disease (CAD) has been historically appraised invasively using angiographic or tomographic estimation (either visual or quantitative) of stenosis severity. ${ }^{1,2}$ However, in the last two decades, invasive assessment of functional significance of CAD has become progressively more clinically relevant, and currently fractional flow reserve (FFR) and instantaneous wave-free ratio (iFR) are considered the reference standards for decision-making in patients with stable CAD. ${ }^{3}$ In particular, iFR is the mean resting distal-to-aortic pressure during a certain portion of diastole called the wave-free period, with results of randomized trials reporting that iFR guided management is non-inferior to FFR guided management in terms of clinical outcomes. ${ }^{4-8}$ Recently, several non- 


\section{COPYRIGHT $^{\circledR} 2021$ EDIZIONI MINERVA MEDICA}

hyperemic pressure ratios (NHPR) have been introduced to quantify the functional significance of CAD. ${ }^{9-12}$ They all showed equivalence to iFR with a mean difference of less than 0.01, despite different calculation algorithms.

The Optowire (Opsens Medical, Québec, ON, Canada) pressure wire system has an optical pressure sensor instead of a conventional piezoresistive pressure sensor, and thus could be less prone to electrical signal drift. ${ }^{13}, 14 \mathrm{~A}$ novel diastolic pressure ratio (dPR) was also recently developed to be used with the Optowire system by Opsens Medical, with potentially superior features to other NHPR indices..$^{15}$ Indeed, as standard NHPR may be more vulnerable to pressure signal drift, with ensuing risks of misclassification for revascularization decisions, the novel Opsens dPR algorithm may have potential advantages to measure the pressure ratio more accurately. ${ }^{16}$

This study aimed to validate the diagnostic performance of the novel Opsens dPR algorithm against iFR in the assessment of the functional significance of intermediate coronary stenoses.

\section{Materials and methods}

\section{Design}

This study included patients from VERIFY 2 (clinicaltrials.gov NCT02377310) ${ }^{17}$ and LATINA, which are prospective registries designed to follow patients after intracoronary pressure assessment of at least one intermediate coronary stenosis (Figure 1). For the purpose of the current study, only patients with valid resting pressure tracings were selected. The study protocol was approved by the institutional review board or ethical committee at each participating center, and all subjects provided written informed consent.

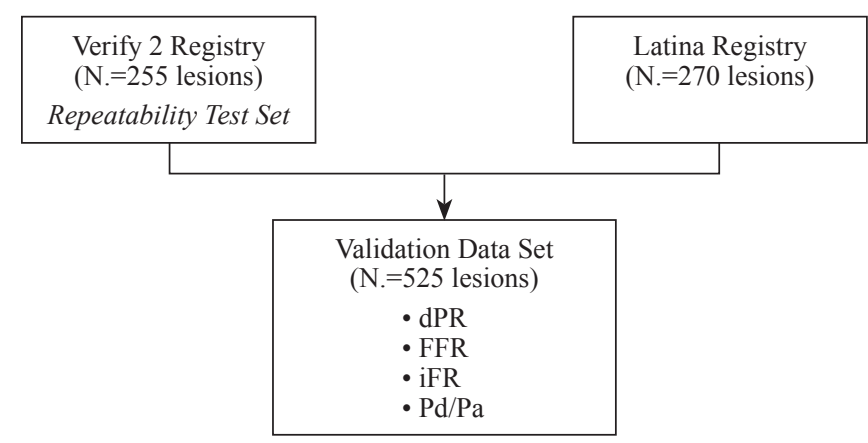

Figure 1.-Study profile.

$\mathrm{dPR}=$ diastolic pressure ratio; $\mathrm{FFR}=$ fractional flow reserve.

iFR: instantaneous wave-free ratio; $\mathrm{Pd} / \mathrm{Pa}$ : distal coronary pressure/aortic pressure.

\section{Measurements}

Pressure measurements were performed according to established methods. ${ }^{5,} 18$ In particular, all pressure measurements were performed using the Prestige or Verrata wire (Philips Volcano, Milan, Italy) and were recorded in the s5 console (Philips Volcano). After administration of intracoronary nitrates (100 to $200 \mu \mathrm{g}$ ), the pressure wire was positioned distal to the target lesion after pressor equalization at the coronary ostium. Initially, whole-cycle resting distal coronary pressure $(\mathrm{Pd})$ /proximal coronary pressure (Pa) was recorded. Whole-cycle resting $\mathrm{Pd} / \mathrm{Pa}$ was calculated using the ratio of the mean Pd to the mean Pa at rest over the entire cardiac cycle. In addition, iFR was calculated as the mean Pd divided by the mean Pa during the diastolic wave-free period, 5,6 and computed using software embedded in the s5 console. After lesion assessment, a drift check was recommended by returning the pressure sensor to the position of equalization. If the pressure ratio exceeded \pm 0.02 , physiological measurements were repeated. After appraisal of NHPR indices, FFR was measured after obtaining maximal hyperemia with intracoronary adenosine as previously described. ${ }^{19}$

After preprocessing of resting pressure waveform tracings, with reviewing and anonymization, valid individual waveforms were transferred to OptoMonitor (Opsens Medical) following standardization of the sampling rate of $125 \mathrm{~Hz}$. All data analyses were performed using a fully automated off-line software algorithm by an independent expert (MV). In particular, Opsens dPR was continuously calculated for every heartbeat using 4 consecutives preceding heartbeats. Diastole period was defined from the nadir of the dicrotic notch $50 \mathrm{~ms}$ before the upstroke of next heartbeat. Calculation of dPR was the based on two phases. The first component was the selection of the analytic beat over 4 consecutive beats. The selected analytic beat corresponded to the median of the combined overall cycle length of 4 consecutive heart beats reordered by (Figure 2):

$$
\left(\frac{\text { mean } \mathrm{Pd} / \mathrm{Pa} \text { at diastole }}{\text { mean } \mathrm{Pd} / \mathrm{Pa} \text { at wholecycle }}\right)
$$

The second component yielded dPR as follows:

$$
\begin{gathered}
\mathrm{dPR}=\left(\frac{\text { mean } \mathrm{Pd} / \mathrm{Pa} \text { at diastole }}{\text { mean Pd/Pa at whole cycle }}\right)_{\text {selected beat among } 4 \text { beats }} \times \\
(\text { mean Pd/Pa at whole cycle })_{\text {over } 4 \text { beats }}
\end{gathered}
$$




\section{COPYRIGHT $^{(\odot)} 2021$ EDIZIONI MINERVA MEDICA}

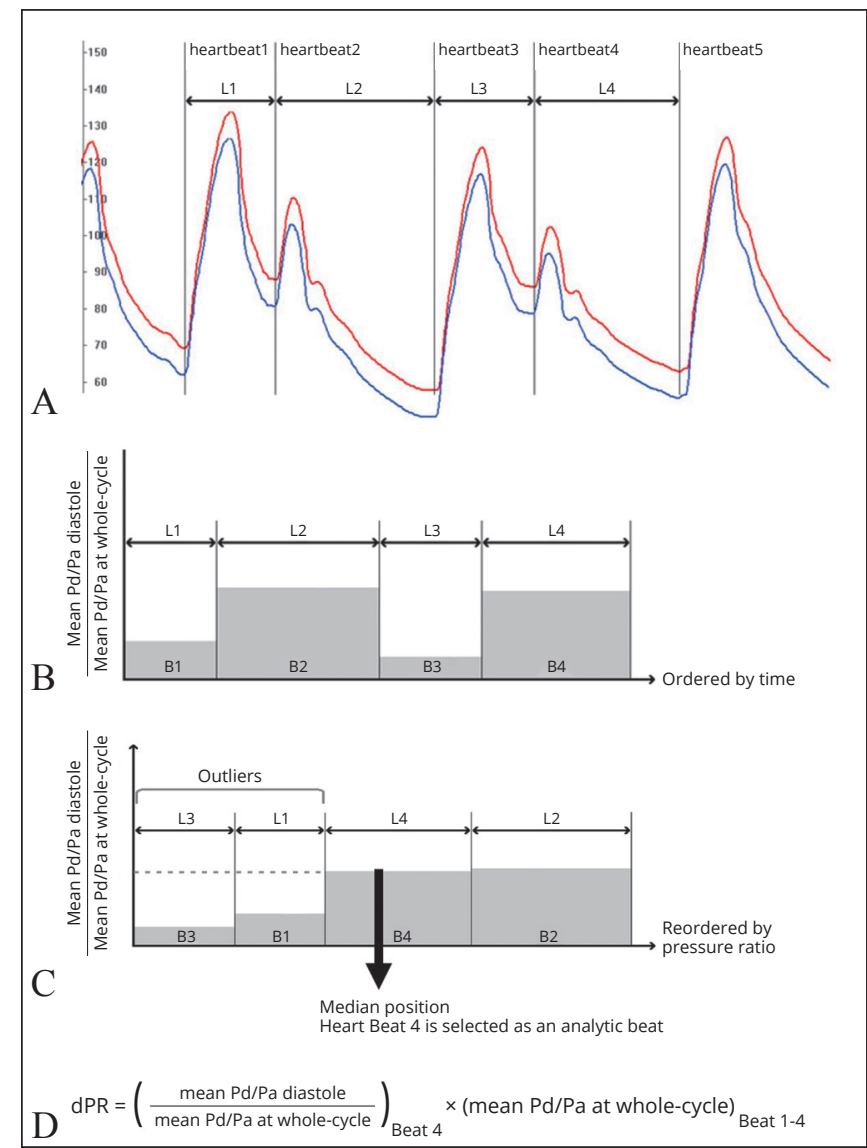

Figure 2.-Diastolic pressure (dPR) ratio computation based on smart median algorithm. A novel dPR is continuously calculated for every heartbeat using 4 consecutive preceding beats. A) The diastole period is defined from the nadir of the dicrotic notch until a few milliseconds before the upstroke of the next heartbeat; B-C) dPR is calculated after selecting the analytic beat that corresponds to the median of the combined overall cycle length of 4 consecutive heart beats reordered by (mean PD/ $\mathrm{Pa}$ at diastole $) /($ mean $\mathrm{PD} / \mathrm{Pa}$ at whole cycle $) ; \mathrm{D}) \mathrm{dPR}$ is thus computed from the selected beat among the 4 consecutive beats. Theoretically, $\mathrm{dPR}$ value is identical to the mean distal coronary pressure/aortic pressure $(\mathrm{Pd} / \mathrm{Pa})$ at diastole when the heart rhythm is regular.

B: beat; L: length.

Finally, retest repeatability of dPR measurements was appraised in the VERIFY 2 dataset, with measurements performed by an independent reader (MV).

\section{Statistical analysis}

Categorical variables are presented as counts and percentages. Continuous patient and procedural characteristics are presented as mean (standard deviation), or median ( 1 st, $3^{\text {rd }}$ quartile). Distributions of physiological assessments are reported by median and interquartile range. Correlations were summarized by linear regression models and the coefficient of determination $\left(\mathrm{R}^{2}\right)$. Systematic differences were assessed by Bland-Altman analysis. Receiver operating characteristic curve (ROC) analysis was performed to examine the agreement of the Opsens dPR using $\mathrm{iFR} \leq 0.89$ and $\mathrm{Pd} / \mathrm{Pa} \leq 0.91$ as reference standards, computing pertinent areas under the curve (AUC), and optimal cutoffs were determined using Youden's Index. ${ }^{20}$ In order to compare the indexes and explain their potential differences, exploratory unsupervised learning analysis was also carried out using principal component analysis, hierarchical clustering and k-means clustering using Euclidean distances. Results are reported as dendrograms, heat map plots, and cluster plots. Statistical significance was set at the 2-tailed 0.05 level, without multiplicity adjustment. Computations were performed with SPSS 21 (IBM, Armonk, NY, USA) and R 3.6 (R Foundation for Statistical Computing, Vienna, Austria).

\section{Results}

From the 2 cohorts, a total of 525 lesions from 479 patients were included (Figure 1; Table I). Notably, mean patient age was 66 years, $84 \%$ were men, $26 \%$ had diabetes, and $45 \%$ presented with stable angina. The left anterior descending artery was the most frequently evaluated vessel (57\%). The median value of iFR was 0.92 (1st quartile $0.87,3$ rd quartile 0.95 ), and the median value of $\mathrm{dPR}$ was $0.92(0.87 ; 0.95)$ (Figure 3$)$.

\section{Diagnostic performance}

Correlation between dPR and iFR was satisfactory (Figure 4), with indices highly correlated $\left(\mathrm{R}^{2}=0.99 ; \mathrm{P}<0.001\right)$. Bland-Altman analysis did not identify systematic differences between $\mathrm{dPR}$ and iFR, with a mean difference of $-0.004 \pm 0.014$ (95\% limits of agreement -0.023 to 0.031 ). A dPR binary threshold of 0.89 provided the optimal cutoff to predict binary iFR $\leq 0.89$. The accuracy of dPR to predict binary iFR was $95.6 \%$, with a sensitivity of $93.5 \%$ and specificity of $96.7 \%$. Compared with resting $\mathrm{Pd} / \mathrm{Pa}$, dPR showed better diagnostic performance (AUC $=0.990$ for Opsens dPR and 0.965 for resting $\mathrm{Pd} / \mathrm{Pa}, \mathrm{P}<0.001$ ) (Figure 5).

Even among lesions $(\mathrm{N} .=246)$ within the $\mathrm{iFR}$ grey zone (0.85-0.93), dPR and iFR were highly correlated $\left(\mathrm{R}^{2}=0.90\right.$, $\mathrm{P}<0.001)$. Only $22(9.0 \%)$ lesions showed binary dPR and iFR discordance; 13 (5.3\%) lesions had a 0.01 difference, $7(2.8 \%)$ had a 0.02 difference, and $2(0.8 \%)$ had a $\geq 0.03$ difference. dPR showed significantly better diagnostic performance than resting $\mathrm{Pd} / \mathrm{Pa}$ for predicting an $\mathrm{iFR} \leq 0.89$ 


\section{COPYRIGHT ${ }^{\odot} 2021$ EDIZIONI MINERVA MEDICA}

OPSENS DPR

VERSACI

TABLE I.-Baseline patient and lesion characteristics. *

\begin{tabular}{lcc}
\hline Parameters & VERIFY 2 Registry & Latina registry \\
\hline Patients & 195 & 284 \\
Age (years) & $66 \pm 10$ & $66 \pm 11$ \\
Male & $183(94 \%)$ & $218(77 \%)$ \\
Smoking & $67(34 \%)$ & $74(26 \%)$ \\
Hypertension & $160(82 \%)$ & $207(73 \%)$ \\
Dyslipidemia & $175(90 \%)$ & $241(85 \%)$ \\
Diabetes mellitus & $43(22 \%)$ & $82(29 \%)$ \\
Family history of coronary artery disease & $164(84 \%)$ & $122(43 \%)$ \\
Prior percutaneous coronary intervention & $76(39 \%)$ & $176(62 \%)$ \\
Prior myocardial infarction & $99(51 \%)$ & $167(59 \%)$ \\
Stable coronary artery disease & $152(60 \%)$ & $65(23 \%)$ \\
Lesions & $255(100 \%)$ & $270(100 \%)$ \\
Left main & $8(3 \%)$ & $11(4 \%)$ \\
Left anterior descending & $153(60 \%)$ & $146(54 \%)$ \\
Left circumflex & $49(19 \%)$ & $51(19 \%)$ \\
Right coronary artery & $45(18 \%)$ & $62(23 \%)$ \\
Intracoronary pressure measurement & & \\
Fractional flow reserve & $0.81(0.75-0.87)$ & \\
Instantaneous wave-free ratio & $0.91(0.87-0.95)$ & \\
Distal coronary pressure/aortic pressure ratio & $0.94(0.91-0.97)$ & \\
Diastolic pressure ratio & $0.92(0.87-0.95)$ & $0.85(0.78-0.90)$ \\
\hline
\end{tabular}

*Reported as mean \pm standard deviation, median (first quartile-third quartile), or count (\%).

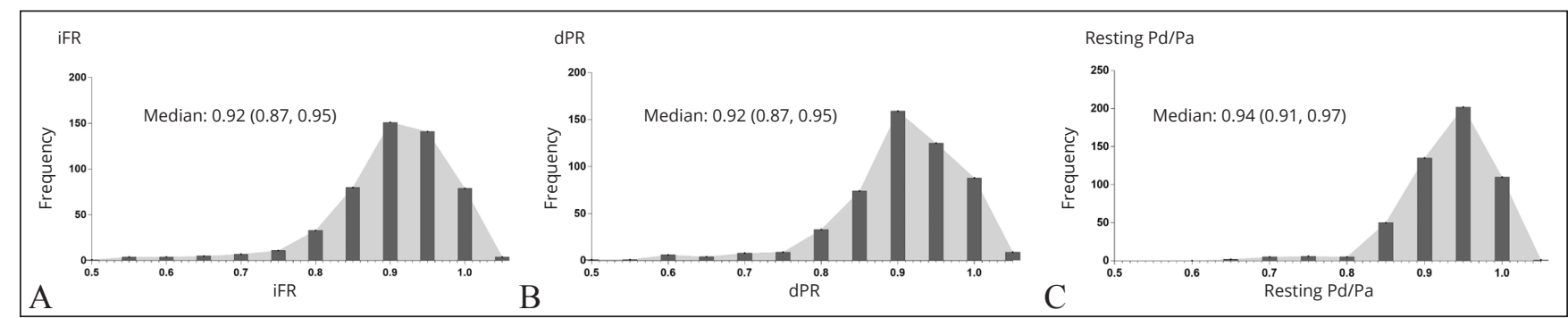

Figure 3.-A) Distribution of the physiologic indices: instantaneous wave-free ratio (iFR); B) diastolic pressure ratio (dPR); C) resting distal coronary pressure/aortic pressure $(\mathrm{Pd} / \mathrm{Pa})$ ratio.

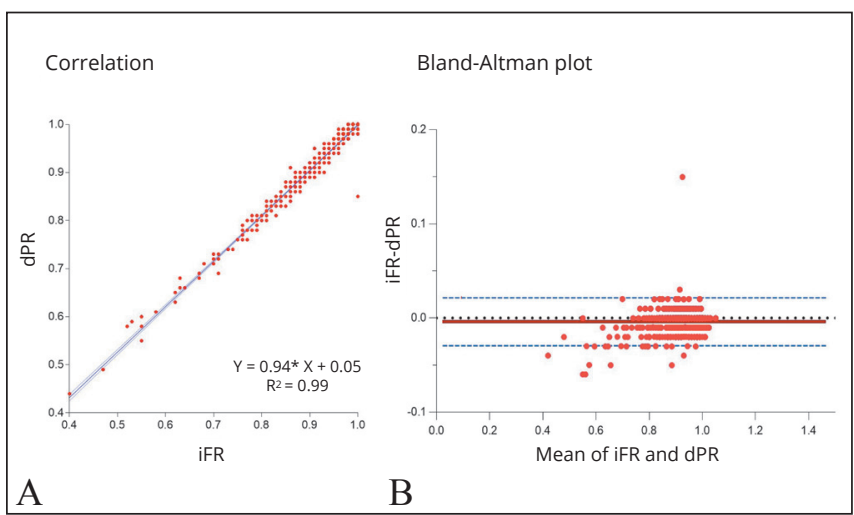

Figure 4.-A) Correlation; and B) Bland-Altman analysis for diastolic pressure ratio (dPR) and instantaneous wave-free ratio (iFR).

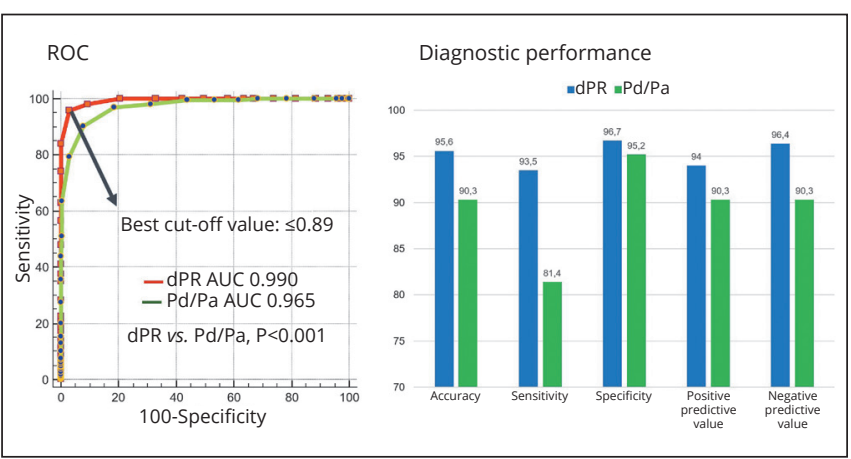

Figure 5.- Receiver operating characteristic curve (ROC) and diagnostic performance of diastolic pressure ratio (dPR) and distal coronary pressure/aortic pressure $(\mathrm{Pd} / \mathrm{Pa})$ ratio in comparison to instantaneous wave-free ratio (iFR). AUC: area under the curve of the ROC. 


\section{COPYRIGHT $^{\circledR} 2021$ EDIZIONI MINERVA MEDICA}

VERSACI

OPSENS DPR

Figure 6.-A) Correlation; B) receiver operating characteristic curve (ROC); and C) diagnostic performance of diastolic pressure ratio (dPR) within the grey zone of the instantaneous wave-free ratio (iFR) $(0.85$ 0.93). AUC: area under the curve of the ROC. Pd/Pa: distal coronary pressure/aortic pressure ratio.

Figure 7.-A) Repeatability of diastolic pressure ratio (dPR); B) instantaneous wave-free ratio (iFR); and C) resting distal coronary pressure/aortic pressure $(\mathrm{Pd} / \mathrm{Pa})$ ratio measurements.
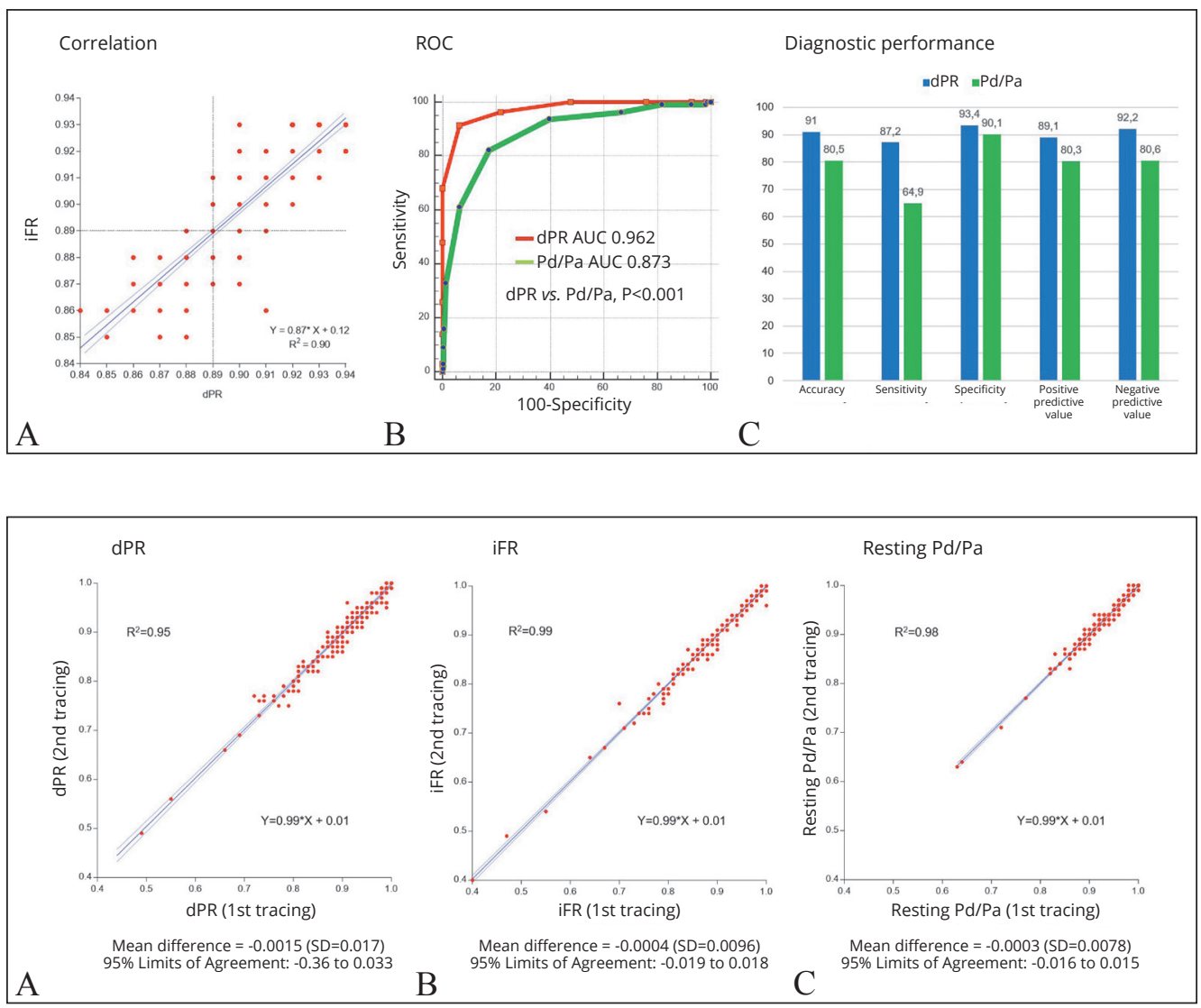

(AUC=0.962 for $\mathrm{dPR}$ and $\mathrm{AUC}=0.873$ for resting $\mathrm{Pd} / \mathrm{P}$, $\mathrm{P}<0.001$ ) (Figure 6). Among the lesions outside the grey zone, only 1 lesion showed discrepancy.

Repeatability and unsupervised learning

Repeatability of dPR was satisfactory, both at visual inspection and actual analysis (Figure 7). In particular, the difference between the test and retest measurements was $-0.0015 \pm 0.017$ for $\mathrm{dPR},-0.0004 \pm 0.0096$ for $\mathrm{iFR}$, and $-0.0003 \pm 0.0078$ for resting $\mathrm{Pd} / \mathrm{Pa}$.

Unsupervised learning was performed first by appraising correlation with dendrograms and heat map plots of features, confirming the strong association between dPR and iFR (Figure 8). Then, principal component analysis was performed, showing that most $(97.2 \%)$ variability in $\mathrm{dPR}, \mathrm{FFR}, \mathrm{iFR}$ and $\mathrm{Pd} / \mathrm{Pa}$ was accounted by the first 2 components (Supplementary Digital Material 1: Supplementary Figure 1). Hierarchical clustering was performed based on such components, identifying several potential clusters, despite the evidence of 3 main ones (Supplemen-

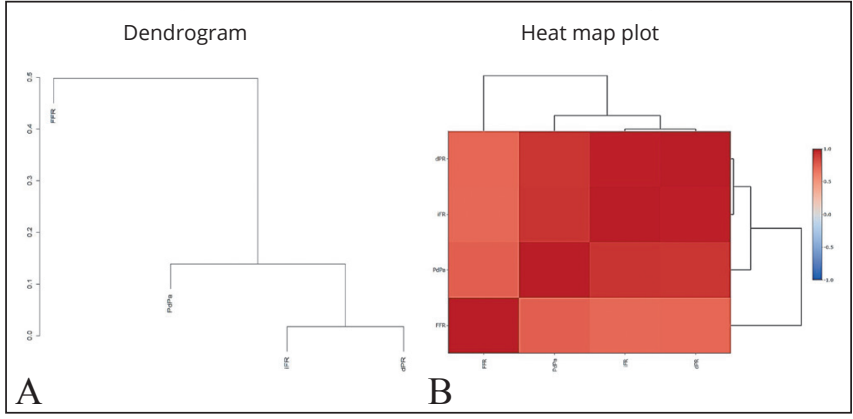

Figure 8.-Dendrogram (A) and heat map plot (B) highlighting the linear correlation (Pearson method) between diastolic pressure ratio (dPR), fractional flow reserve (FFR), instantaneous wave-free ratio (iFR), and distal coronary pressure/aortic pressure $(\mathrm{Pd} / \mathrm{Pa})$ ratio.

tary Digital Material 2: Supplementary Figure 2, Supplementary Figure 3). Notably, correlation between iFR and $\mathrm{dPR}$ was strong irrespective of the chosen cluster, whereas it proved much weaker between iFR and $\mathrm{Pd} / \mathrm{Pa}$, especially in those with very low iFR values (Supplementary Digital Material 3: Supplementary Figure 4). Results of k-means 


\section{COPYRIGHT $^{(\odot)} 2021$ EDIZIONI MINERVA MEDICA}

clustering yielded similar results (Supplementary Digital Material 4: Supplementary Figure 5, Supplementary Figure 6, Supplementary Figure 7).

\section{Discussion}

This study suggests that the present novel algorithm developed by Opsens Medical for dPR computation is numerically and diagnostically equivalent to iFR. Even in the range of the iFR grey zone, Opsens dPR was strongly associated with iFR, with limited bias. In addition, compared with whole-cycle resting $\mathrm{Pd} / \mathrm{Pa}$, $\mathrm{dPR}$ showed better diagnostic performance to predict binary iFR. Therefore, pending further corroborating evidence from prospective observational studies and randomized trials, this novel dPR algorithm can be considered as a useful adjunct for decision making in patients with $\mathrm{CAD}$, as an alternative to iFR.

Randomized trials have showed that iFR-guided percutaneous coronary intervention was non-inferior to FFRguided percutaneous coronary intervention regarding clinical events, such that clinical guidelines recommended the iFR as an IA indication for revascularization decision. ${ }^{5-8}$ The favorable features of NHPR have pushed several groups to develop other NHPR. Whole-cycle resting Pd/ $\mathrm{Pa}$, which has a substantial clinical and regulatory support, has been shown to be very closely related and transformable to iFR. ${ }^{21}$ However, whole-cycle resting $\mathrm{Pd} / \mathrm{Pa}$ is less sensitive to detect a difference in stenosis severity compared with iFR. ${ }^{22}$ Sub-cycle NHPR have their own unique calculation metrics including average $\mathrm{Pd} / \mathrm{Pa}$ over a certain period of diastole, 9,12 an instant lowest $\mathrm{Pd} / \mathrm{Pa}$ sample during the entire cardiac cycle, ${ }^{10}$ and average $\mathrm{Pd} / \mathrm{Pa}$ when $\mathrm{Pa}$ is less than the mean $\mathrm{Pa}$ and there is down-sloping Pa. ${ }^{11}$ Nevertheless, they all showed $<0.01$ difference with the iFR and an AUC $>0.99$ to predict binary iFR, which indicates numerical and clinical equivalence between iFR and other NHPR.

This study introduced another NHPR using a different analytic algorithm. The novel algorithm for dPR computation showed a mean difference of $0.004 \pm 0.014$ with iFR and an accuracy of $96 \%$ to predict binary iFR cutoff values. Even in the range of the grey zone (0.85-0.93), diagnostic accuracy was maintained (91\%). Only $0.5 \%$ lesions had $a \geq 0.03$ difference between the novel dPR and iFR, but whether these differences would have impacted on decision making or clinical outcomes is uncertain. Compared with other NHPR, the Opsens dPR algorithm has several potential advantages. First, this is a dedicated algorithm for optical pressure sensor technology, which has been considered less susceptible to signal drift during pressure measurement. Therefore, NHPR measurement using an optical pressure sensor may be more accurate and safer in daily practice, as the NHPR has a narrow diagnostic range and the potential risk for misclassification of the revascularization decision due to signal drift is clinically relevant in NHPR measurement. Second, the novel dPR does not require a quality electrocardiogram. Instead, the dicrotic notch detection method is used to detect diastolic periods. Third, this index introduced the unique selection algorithm of the most appropriate heartbeat without the need for analyzing and rejecting heart beats with irregular or outlier signals. Therefore, it could theoretically provide more consistent value in cases of arrhythmic heart beats or signal noises. Particularly, this benefit would be clinically relevant to perform pressure wire pullback to evaluate tandem lesions. However, these arguments remain currently hypothetical. Thus, further studies will be needed to validate these advantages and how these translate into clinically relevant outcomes.

Although this novel dPR algorithm is highly predictive of iFR, the physiologic meaning of this novel dPR needs further evaluation as well. ${ }^{3}$ In addition, our finding of numerical equivalence between the novel $\mathrm{dPR}$ and $\mathrm{iFR}$ is against the fundamental hypothesis of a "wave-free period" in the development of iFR, because the novel dPR is basically calculated from the entire diastolic period. Inherently, the novel dPR had considerable discordance with the FFR. As discordance is associated with coronary risk factors, including lesion territory, age, gender, and diabetes, ${ }^{21}$ further clinical studies are needed, focusing on discordant cases in a large population. In addition, similar to decision making with iFR, a hybrid approach using selective hyperemia may provide a compromise between the discordance of the novel $\mathrm{dPR}$ and inconvenience of systematic hyperemic stimulation. Nevertheless, the present study support expanding the clinical use of the NHPR to physicians who use the optical pressure wire system in their clinical practice. ${ }^{23}$

\section{Limitations of the study}

This study has several limitations. First, this is a posthoc analysis from prospectively collected data. Second, since the number of valid non-hyperemic resting pressure tracings was relatively limited compared with the total registry population, selection bias cannot be completely excluded. Third, pressure tracings were obtained by the 


\section{COPYRIGHT $^{(\odot)} 2021$ EDIZIONI MINERVA MEDICA}

Philips Volcano Prestige or Verrata wire. Further studies should be conducted using the Opsens Optowire pressure wire system to prove the potential advantage of the novel dPR with a smart median algorithm using the dedicated guidewire from Opsens Medical. Finally, physicians should remain aware that FFR or NHPR cannot reliably measure microvascular dysfunction or diffuse atherosclerotic disease. ${ }^{24-26}$

\section{Conclusions}

In conclusion, this multicenter registry suggests this novel dPR algorithm may yield results which are clinically equivalent to the iFR. Pending further corroborating studies, physicians may routinely consider this dPR algorithm to gauge the functional significance of a coronary lesion.

\section{References}

1. Biondi-Zoccai G, Versaci F, Iskandrian AE, Schillaci O, Nudi A, Frati $\mathrm{G}$, et al. Umbrella review and multivariate meta-analysis of diagnostic test accuracy studies on hybrid non-invasive imaging for coronary artery disease. J Nucl Cardiol 2020;27:1744-55.

2. Garrone P, Biondi-Zoccai G, Salvetti I, Sina N, Sheiban I, Stella PR, et al. Quantitative coronary angiography in the current era: principles and applications. J Interv Cardiol 2009;22:527-36.

3. Kern MJ, Seto AH. Is Instantaneous Wave-Free Ratio a New Standard of Care for Physiologic Assessment of Coronary Lesions? More Questions Than Answers. Circulation 2017;136:2295-7.

4. Sen S, Escaned J, Malik IS, Mikhail GW, Foale RA, Mila R, et al. Development and validation of a new adenosine-independent index of stenosis severity from coronary wave-intensity analysis: results of the ADVISE (ADenosine Vasodilator Independent Stenosis Evaluation) study. J Am Coll Cardiol 2012;59:1392-402.

5. Davies JE, Sen S, Dehbi HM, Al-Lamee R, Petraco R, Nijjer SS, et al. Use of the Instantaneous Wave-free Ratio or Fractional Flow Reserve in PCI. N Engl J Med 2017;376:1824-34.

6. Götberg M, Christiansen EH, Gudmundsdottir IJ, Sandhall L, Danielewicz M, Jakobsen L, et al.; iFR-SWEDEHEART Investigators. Instantaneous Wave-free Ratio versus Fractional Flow Reserve to Guide PCI. N Engl J Med 2017;376:1813-23.

7. Neumann FJ, Sousa-Uva M, Ahlsson A, Alfonso F, Banning AP, Benedetto U, et al. 2018 ESC/EACTS Guidelines on myocardial revascularization. EuroIntervention 2019;14:1435-534.

8. Patel MR, Calhoon JH, Dehmer GJ, Grantham JA, Maddox TM, Maron DJ, et al. ACC/AATS/AHA/ASE/ASNC/SCAI/SCCT/STS 2017 Appropriate Use Criteria for Coronary Revascularization in Patients With Stable Ischemic Heart Disease: A Report of the American College of Cardiology Appropriate Use Criteria Task Force, American Association for Thoracic Surgery, American Heart Association, American Society of Echocardiography, American Society of Nuclear Cardiology, Society for Cardiovascular Angiography and Interventions, Society of Cardiovascular Computed Tomography, and Society of Thoracic Surgeons. J Am Coll Cardiol 2017;69:2212-41.

9. Van't Veer M, Pijls NH, Hennigan B, Watkins S, Ali ZA, De Bruyne B, et al. Comparison of Different Diastolic Resting Indexes to iFR: Are They All Equal? J Am Coll Cardiol 2017;70:3088-96.
10. Svanerud J, Ahn JM, Jeremias A, van 't Veer M, Gore A, Maehara $\mathrm{A}$, et al. Validation of a novel non-hyperaemic index of coronary artery stenosis severity: the Resting Full-cycle Ratio (VALIDATE RFR) study. EuroIntervention 2018;14:806-14.

11. Johnson NP, Li W, Chen X, Hennigan B, Watkins S, Berry C, et al. Diastolic pressure ratio: new approach and validation vs. the instantaneous wave-free ratio. Eur Heart J 2019;40:2585-94.

12. Ligthart J, Masdjedi K, Witberg K, Mastik F, van Zandvoort L, Lemmert ME, et al. Validation of Resting Diastolic Pressure Ratio Calculated by a Novel Algorithm and Its Correlation With Distal Coronary Artery Pressure to Aortic Pressure, Instantaneous Wave-Free Ratio, and Fractional Flow Reserve. Circ Cardiovasc Interv 2018;11:e006911.

13. Kern MJ. Comparing FFR tools: new wires and a pressure microcatheter. Cathet Lab Digest 2016;24:4-9.

14. Menon M, Jaffe W, Watson T, Webster M. Assessment of coronary fractional flow reserve using a monorail pressure catheter: the first-inhuman ACCESS-NZ trial. EuroIntervention 2015;11:257-63.

15. Ulacia $P$, Rimac G, Lalancette $S$, Belleville $C$, Mongrain R, Plante $S$, et al. A novel fiber-optic based 0.014 " pressure wire: designs of the OptoWire ${ }^{\mathrm{TM}}$, development phases, and the $\mathrm{O} 2$ first-in-man results. Catheter Cardiovasc Interv 2020. [Epub ahead of print]

16. Cook CM, Ahmad Y, Shun-Shin MJ, Nijjer S, Petraco R, Al-Lamee R, et al. Quantification of the Effect of Pressure Wire Drift on the Diagnostic Performance of Fractional Flow Reserve, Instantaneous Wave-Free Ratio, and Whole-Cycle Pd/Pa. Circ Cardiovasc Interv 2016;9:e02988.

17. Hennigan B, Oldroyd KG, Berry C, Johnson N, McClure J, McCartney $\mathrm{P}$, et al. Discordance Between Resting and Hyperemic Indices of Coronary Stenosis Severity: The VERIFY 2 Study (A Comparative Study of Resting Coronary Pressure Gradient, Instantaneous Wave-Free Ratio and Fractional Flow Reserve in an Unselected Population Referred for Invasive Angiography). Circ Cardiovasc Interv 2016;9:004016.

18. Tonino PA, De Bruyne B, Pijls NH, Siebert U, Ikeno F, van't Veer $\mathrm{M}$, et al.; FAME Study Investigators. Fractional flow reserve versus angiography for guiding percutaneous coronary intervention. N Engl J Med 2009;360:213-24.

19. Novara M, D'Ascenzo F, Gonella A, Bollati M, Biondi-Zoccai G, Moretti C, et al. Changing of SYNTAX score performing fractional flow reserve in multivessel coronary artery disease. J Cardiovasc Med (Hagerstown) 2012;13:368-75.

20. Biondi-Zoccai G. Diagnostic Meta-Analysis - A Useful Tool for Clinical Decision-Making. Cham: Springer International Publishing; 2018.

21. Kobayashi Y, Johnson NP, Zimmermann FM, Witt N, Berry C, Jeremias A, et al.; CONTRAST Study Investigators. Agreement of the Resting Distal to Aortic Coronary Pressure With the Instantaneous Wave-Free Ratio. J Am Coll Cardiol 2017;70:2105-13.

22. Lee JM, Park J, Hwang D, Kim CH, Choi KH, Rhee TM, et al. Similarity and Difference of Resting Distal to Aortic Coronary Pressure and Instantaneous Wave-Free Ratio. J Am Coll Cardiol 2017;70:2114-23. 23. Kim JH, Choi W, Kim KC, Nam CW, Hong BK, Kim JH, et al. The Current Status of Intervention for Intermediate Coronary Stenosis in the Korean Percutaneous Coronary Intervention (K-PCI) Registry. Korean Circ J 2019;49:1022-32.

24. Stepien K, Nowak K, Skorek P, Baravik V, Kozynacka A, Nessler J, et al. Baseline indicators of coronary artery disease burden in patients with non-ST-segment elevation acute coronary syndrome. Minerva Cardioangiol 2019;67:181-90.

25. Biondi Zoccai G, Carnevale R, Vitali M, Tritapepe L, Martinelli O, Macrina $\mathrm{F}$, et al. A randomized trial comparing the acute coronary, systemic, and environmental effects of electronic vaping cigarettes versus heat-not-burn cigarettes in smokers of combustible cigarettes undergoing invasive coronary assessment: rationale and design of the SUR-VAPES 3 trial. Minerva Cardioangiol 2020;68:548-55.

26. Shlofmitz E, Kuku KO, Waksman R, Garcia-Garcia HM. Intravascular ultrasound-guided drug-eluting stent implantation. Minerva Cardioangiol 2019;67:306-17. 


\section{COPYRIGHT ${ }^{\circledR} 2021$ EDIZIONI MINERVA MEDICA}

OPSENS DPR

VERSACI

Conflicts of interest.-Marcel van't Veer received speaker fees from Abbott; Sébastien Lalancette is a full-time employee of Opsens Medical; Keith Oldroyd received grants/research supports from Boston Scientific and honoraria or consultation fees from Abbott and Biosensor; Giuseppe Biondi Zoccai consulted for Cardionovum, InnovHeart, Meditrial, and Replycare; all other authors report no conflict of interest.

Funding.-This work was supported by Opsens Medical.

Authors' contributions.-Francesco Versaci, Micaela Conte, Marcel van't Veer, Sébastien Lalancette, Keith Oldroyd, Simone Calcagno and Giuseppe Biondi Zoccai have given substantial contributions to data collection and analysis, manuscript writing and revision, Giuseppe Biondi Zoccai drafted the final version of the manuscript. All authors read and approved the final version of the manuscript.

History.-Manuscript accepted: November 27, 2020. - Manuscript received: November 2, 2020.

Supplementary data.-For supplementary materials, please see the HTML version of this article at www.minervamedica.it 